\title{
A IMPORTÂNCIA DO ENFERMEIRO NA PREVENÇÃO DO CÂNCER DE COLO DO ÚTERO
}

\section{ARTIGO ORIGINAL}

NASCIMENTO, Nathália de Souza Santos ${ }^{1}$

NASCIMENTO, Nathália de Souza Santos. A importância do enfermeiro na prevenção do câncer de colo do útero. Revista Científica Multidisciplinar Núcleo do Conhecimento. Ano 06, Ed. 06, Vol. 15, pp. 73-88. Junho de 2021. ISSN: 2448-0959, Link de acesso: https://www.nucleodoconhecimento.com.br/saude/enfermeiro-naprevencao, DOI: 10.32749/nucleodoconhecimento.com.br/saude/enfermeiro-naprevencao

\section{RESUMO}

Trata-se de um estudo sobre a importância do Enfermeiro na prevenção do câncer de colo do útero. O objetivo da pesquisa é discutir a efetividade do enfermeiro na promoção e prevenção do câncer de colo do útero, tendo como objeto de estudo, o Enfermeiro na prevenção. Utilizou-se como metodologia uma pesquisa bibliográfica com abordagem qualitativa, do tipo descritivo e exploratório. O câncer de colo do útero é uma lesão precursora no seu epitélio, mais precisamente na junção escamo colunar (JEC) sendo um grande problema de saúde atingindo toda a população mundial, pois apresenta alto índice de letalidade entre mulheres de várias idades. Pode-se concluir com este estudo, que a ação do enfermeiro como educador é primordial para a diminuição da incidência de mulheres acometidas pelo câncer cérvico-uterino, fazendo com que a mulher não tenha que realizar tratamentos para a cura do câncer, o que pode ser evitado com as atividades educativas e a realização do exame de Papanicolau. Ressalta-se ainda que é essencial inserir o homem e conscientizar a

\footnotetext{
${ }^{1}$ Graduada em Enfermagem pela UNIABEU.
}

RC: 89652

Disponível em: https://www.nucleodoconhecimento.com.br/saude/enfermeiro-na-prevencao 
população dos benefícios de se prevenir contra as doenças precursoras como o HPV e o câncer de colo do útero, no sentido de minimizar a incidência da doença.

Palavras-chaves: Câncer, Colo, Prevenção, Papanicolau, Enfermeiro.

\section{INTRODUÇÃO}

O Ministério da Saúde (2016) relata que os programas de atenção básica à saúde, voltados para esferas individuais e coletivas, concentram-se na oferta do cuidado de forma a promover subsídios para haver a oferta e assistência à saúde, redução dos possíveis danos, direcionando o fluxo nas redes de saúde.

Os programas de atenção básica à saúde, são desenvolvidos através de atividades realizadas por equipes multiprofissionais estabelecendo limites da área onde o serviço será implementado, levando em conta todas as especificidades desses locais (MINISTÉRIO DA SAUDE, 2016).

O Sistema Único de Saúde (SUS) precisa abranger ações assistências ou de caractere curativo, priorizando a saúde e prevenção de doenças. Desta forma, visase à atenção básica para a sociedade e busca-se definir áreas estratégicas para eliminação e tratamento de doenças como: hanseníase, tuberculose, hipertensão, diabetes, desnutrição, cuidados com a saúde infantil, da mulher e do idoso, além de tratamentos odontológicos (BRASIL, Lei n.. 8.080/1990).

Segundo relatório da Agência Internacional para Pesquisa em Câncer o impacto global do câncer de colo do útero tem aumentado significativamente nos últimos anos, esse índice está intimamente ligado a mudanças do perfil da sociedade moderna, um aumento exagerado no uso de produtos químicos e etc. Uma marcante característica do câncer do colo do útero é a sua consistente associação, em todas as regiões do mundo, com o baixo nível socioeconômico, ou seja, com os grupos que têm maior vulnerabilidade social. São nesses grupos que se concentram as maiores barreiras de

RC: 89652

Disponível em: https://www.nucleodoconhecimento.com.br/saude/enfermeiro-na-prevencao 
acesso à rede de serviços para detecção e tratamento precoce da doença e de suas lesões precursoras (INCA, 2020).

A motivação para a realização do presente estudo deu-se durante o estágio no módulo de Saúde da Mulher, onde observamos que algumas mulheres não realizavam o exame preventivo (Papanicolau) periodicamente por falta de informação e assim constituíam um grupo de risco para o câncer de colo do útero.

Em 28 de Março de 2006 o governo emitiu a Portaria № 648, onde ficava estabelecido que o Programa saúde da família hoje conhecido como estratégia saúde da família, configuraria estratégia prioritária do Ministério da Saúde para organizar os serviços de saúde, através da reorientação da Atenção Básica. Dentre alguns desafios para se alcançar integralidade na assistência à saúde da mulher na Atenção Básica estão às ações de controle dos cânceres do colo do útero e da mama. O câncer está entre as principais causas de morte na população feminina e, a mudança de hábitos, aliada ao estresse gerado pelo estilo de vida do mundo moderno, contribuem diretamente na incidência dessa doença. (MINISTÉRIO DA SAUDE, 2016).

É válido mencionar que dentre os programas voltados para a saúde da mulher, inclui ações sociais educacionais em prevenção, diagnósticos, além do tratamento e recuperação de sua saúde. Uma das ações é o tratamento ginecológico, acompanhamento de pré-natal, planejamento familiar, além de outras necessidades (BRASIL, 2016).

Surge então a seguinte questão norteadora: Quais as práticas educativas utilizadas pelo enfermeiro podem estimular as mulheres a realizarem o Exame Preventivo?

A fim de responder a questão gerada neste estudo, configurou-se o seguinte objetivo: Discutir a efetividade do enfermeiro na promoção e prevenção do câncer de colo do útero. Esta pesquisa dar-se à sobre o seguinte objeto de estudo: O enfermeiro na prevenção de câncer de colo do útero.

RC: 89652

Disponível em: https://www.nucleodoconhecimento.com.br/saude/enfermeiro-na-prevencao 
Esta pesquisa contribuirá para a academia como material auxiliar no esclarecimento e aprimoramento de conhecimentos sobre a importância da prevenção do câncer de colo do útero, onde o leitor poderá buscar informações para aperfeiçoar a prática. $E$ também será relevante para despertar o interesse de novas publicações científicas acerca desta temática.

Para a sociedade está pesquisa contribuirá a fim de que as informações a respeito do câncer de colo do útero, suas complicações e a importância do exame preventivo, possam ser aceitas quando passadas por qualquer profissional da enfermagem. Viabilizando assim o fluxo da informação na sociedade. Servirá para que de fato estreitem-se os laços entre esta população e os serviços de saúde.

Contribui para a enfermagem, ao demonstrar a necessidade de se aproximar do cotidiano das mulheres a fim de salientar a importância de ações educativas eficazes voltadas para o planejamento.

\section{METODOLOGIA}

Trata-se de uma pesquisa bibliográfica com abordagem qualitativa, do tipo descritivo e exploratório, acerca da importância do enfermeiro na prevenção do câncer de colo de útero.

A pesquisa qualitativa trabalha com dados subjetivos, crenças, valores, opiniões, fenômenos e hábitos (DENZIN, 2006). As pesquisas exploratórias têm como principal finalidade desenvolver, esclarecer e modificar conceitos e ideias, tendo em vista a formulação de problemas mais precisos às hipóteses pesquisáveis para estudos posteriores (GIL, 1999).

De acordo com Gil (2007), a pesquisa descritiva tem como principal objetivo a descrição das características de determinada população ou fenômeno, ou então, o estabelecimento de relações variáveis. Para a obtenção dos dados utilizou-se como fonte de pesquisa a Biblioteca Virtual de Saúde (BVS), nas bases de dados: Scientific

RC: 89652

Disponível em: https://www.nucleodoconhecimento.com.br/saude/enfermeiro-na-prevencao 
Eletronic Library Online (SCIELO) e Literatura Latino-Americana e do Caribe em Ciências da Saúde (LILACS). A coleta dos dados ocorreu no período de fevereiro a junho de 2021.

Neste estudo destacam-se como critérios de inclusão os artigos científicos publicados em língua portuguesa, os artigos que tivessem relação com o tema e com os seguintes descritores: Câncer + colo + prevenção + enfermeiro. No entanto, foi excluída a maioria dos artigos científicos inferiores ao ano de 2016, os que não estivessem relacionados com a temática abordada, escritos em outros idiomas e com textos incompletos.

Através do levantamento dos dados, foi obtido um quantitativo total de 924 artigos científicos encontrados. Dentre esses, foram encontrados 202 artigos na Scielo, sendo aproveitados 08 e excluídos 194, pois não se adequaram aos critérios de inclusão citados acima.

$\mathrm{Na}$ Lilacs encontrou-se 722 artigos científicos, sendo 02 selecionados e excluídos 720 artigos, pois não estão relacionados com o tema.

Portanto, fez-se necessário buscar bases bibliográficas para complementar e fundamentar este estudo, pois somente os artigos científicos não respondiam a questão abordada nesta pesquisa. Utilizaram-se literaturas referentes ao carcinoma de colo de útero com delimitação temporal compreendida nos anos de 2016 a 2021.

Optamos pela delimitação temporal no período relacionado devido nesta época ter sido aprovada a Política Nacional de Atenção Básica publicada na Portaria no 648/GM em 28 de março de 2006, estabelecendo a revisão de diretrizes e normas para a organização da Atenção Básica para o Programa Saúde da Família (PSF) e o Programa Agentes Comunitários de Saúde (PACS).

RC: 89652

Disponível em: https://www.nucleodoconhecimento.com.br/saude/enfermeiro-na-prevencao 


\section{REVISÃO DE LITERATURA}

\subsection{O CÂNCER NO BRASIL}

Pode-se dizer que a soma de mais de 100 doenças é denominada câncer, por ocorrerem crescimentos desalinhados das células, acometendo outros órgãos. Devido a esse crescimento desordenado, ocorre a formação de tumores malignos que em alguns casos avançados pode ocorrer metástases.

Vários fatores podem contribuir para o aparecimento do câncer, podendo ser eles externos ou internos ao organismo. A forma como ser humano se comporta em relação à alimentação, aos costumes e os hábitos do meio onde vive são entendidos como fatores externos. Já os fatores internos são ocasionados principalmente através da pré-disposição genética e do organismo conseguir atacar e se defender de forma eficiente (INCA, 2019).

Segundo o INCA (2019), o câncer é uma doença degenerativa, que pode surgir em qualquer parte do corpo. Porém relações com o pulmão, mama, colo do útero, próstata e o reto são mais comuns. O tumor possui tipos diferenciados, sendo menos ou mais agressivos. Cada paciente pode apresentar um quadro crônico totalmente diferente para o mesmo local da doença.

\subsubsection{INCIDÊNCIA DE CÂNCER DE MAMA NO BRASIL}

Em 2019, o INCA publicou a incidência do câncer de mama (Figura 01) ocorrido em mulheres acima de 40 anos. A taxa de mortalidade vem crescendo ano após ano, é já e considerada uma das maiores taxas de mortalidade por câncer no Brasil.

RC: 89652

Disponível em: https://www.nucleodoconhecimento.com.br/saude/enfermeiro-na-prevencao 
Figura 1 - Taxas de mortalidade por câncer de mama feminina, específicas por faixas etárias, por 100.000 mulheres. Brasil, 1979 a 2019

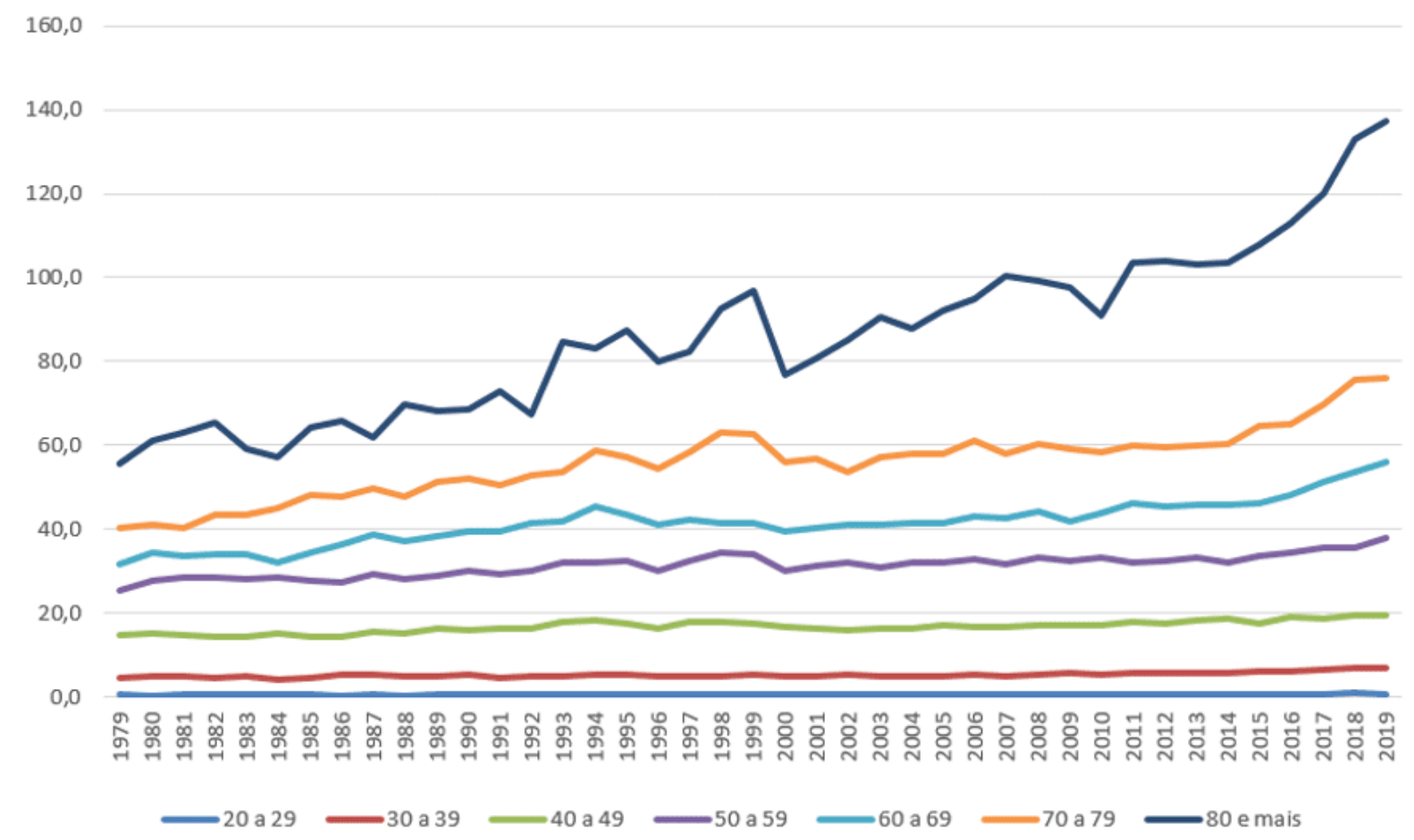

Fonte: INCA (2019) - modelo adaptado pelo autor.

Por ser o primeiro tumor mais frequente na população feminina e a quarta morte de mulheres por câncer no Brasil, o país vem avançando na sua capacidade de realização de diagnósticos precoce. É válido mencionar que em quase todas as regiões do Brasil, o câncer de mama possui o maior número de incidentes, onde apenas na região norte, o número maior e do câncer de colo de útero.

\subsubsection{PREVENÇÃO CONTRA O CÂNCER DE COLO DO ÚTERO}

Devido aos relatos de aumento excessivo de mulheres acometidas pelo câncer de colo do útero, foram implantados medidas e programas no serviço de saúde pública para que ocorresse a diminuição dos índices da patologia. Por corresponder $24 \%$ de todos os cânceres em media no Brasil, o câncer de colo de útero é o mais comum entre as mulheres.

RC: 89652

Disponível em: https://www.nucleodoconhecimento.com.br/saude/enfermeiro-na-prevencao 
Para (INCA, 2021), com uma rotina estabelecida periodicamente, a mulher pode facilmente descobrir se há alguma mutação celular através do exame de Papanicolau, popularmente conhecido como exame preventivo. Dessa forma é possível tratar precocemente o câncer do colo do útero, chamado também de câncer cervical, que pode demorar anos para se desenvolver.

Através do INCA em parceria com o Ministério da Saúde, foi implementado um programa denominado Viva Mulher em 1997 (INCA, 1997). O programa visa através de regiões brasileiras, realizar exames preventivos contra o câncer em mulheres de 25 anos até os 64 anos. Na ocasião (época), todas as mulheres que apresentavam resultados negativos por 2 vezes seguidas, eram dispensadas do exame adicional.

A faixa etária priorizada no rastreamento do câncer do colo do útero foi estipulada com base em estudos, que apresentaram ser de baixa eficiência o rastreamento de mulheres de faixa etária abaixo dos 25 anos para reduzir a ocorrência desse câncer, observado que as lesões preeminentes são minimamente invasivas e a maior parte regride naturalmente de seis a dezoito meses (SOOST et al, 1991).

\subsection{ATENÇÃO INTEGRAL À SAÚDE DA MULHER}

Considerando os princípios da atenção básica a enfermagem pode contribuir a fim de melhorar toda a qualidade dos serviços de saúde, mediante o processo educativo aumentando a resolutividade dos serviços prestados aos usuários, considera o sujeito em sua singularidade, complexidade e integralidade, sempre buscando a promoção básica à saúde e bem-estar, tratando doenças e principalmente prevenindo contra essas enfermidades (BRASIL, 2006).

O câncer de colo do útero ocorre principalmente em mulheres jovens, com pico de incidência em torno dos 30 anos; recentemente, tem-se observado maior frequência em torno dos 20 anos e, ocasionalmente, em mais jovens (HERBST et al. 2000).

RC: 89652

Disponível em: https://www.nucleodoconhecimento.com.br/saude/enfermeiro-na-prevencao 
As ações voltadas para a saúde da mulher também foram priorizadas na publicação da Norma Operacional de Assistência à Saúde (NOAS), em 2001, caracterizando como uma das responsabilidades da ESF (Estratégia Saúde da Família) a PCCU (Prevenção do câncer do colo de útero), indicando, como atividades básicas, o rastreamento de câncer de colo uterino, a coleta de material para exame citológico e alimentação dos sistemas de informação (BRASIL, 2006).

Pressupõem-se então que a ESF trabalha para garantir o acesso, visando vínculo e humanização e reúne condições para qualificar as práticas de PCCU.

\title{
3.3 O PAPEL DO ENFERMEIRO NA PREVENÇÃO DO CÂNCER DE COLO DO ÚTERO
}

Segundo o Ministério da Saúde, a enfermagem está sendo motivo de várias pesquisas sobre sua atuação na prevenção do câncer, evidenciada a sua importância nessa prevenção, atuando juntamente com a população como conselheiro e educador.

\begin{abstract}
$\mathrm{Na}$ medida em que as mulheres se deparam com mudanças importantes nas suas funções, devido a sua inclusão no mercado de trabalho, elas assumem novas condutas nos cuidados de sua saúde. A enfermagem acompanhando essas mudanças, cada vez mais perto, seja na clínica da família ou na empresa onde esta mulher trabalha torna-se cada vez mais importante nos cuidados preventivos às mulheres, encorajando-as e orientando sobre a importância de realizar o exame ginecológico, atrelado a consulta da mulher periodicamente conforme descreve a Política Nacional de Saúde das Mulheres, ensinando sobre a saúde e doença, fornecendo suporte, aconselhamento e monitorização contínua, realizando a promoção de práticas e comportamentos positivos em relação à saúde reprodutiva e sexual (SMELTZER; BARE, 2002)
\end{abstract}

Como aponta Cestari (2005), o comportamento preventivo está intimamente relacionado a fatores sociais, psicológicos, ambientais e culturais. É comum e corriqueiro escutar de alguns profissionais de saúde dizer que o exame Papanicolau é indolor e de rápida execução, porém não só aparte técnica dever ser considerada, mas também, os conflitos psicológicos que permeiam essa mulher sobre o exame.

$\mathrm{RC}: 89652$

Disponível em: https://www.nucleodoconhecimento.com.br/saude/enfermeiro-na-prevencao 
Helbst (2000), destaca que para que o programa de prevenção do câncer do colo do útero funcione de maneira correta, é necessário que se tenha uma estrutura harmoniosa, e financeiramente estruturada, para que possa capacitar profissionais, recursos e equipamentos, proporcionando um atendimento para a sociedade mais justa e adequada.

Segundo COFEN-12 (2015), o profissional enfermeiro é capacitado para realizar a consulta de enfermagem e sendo necessário também realizar o exame preventivo Papanicolau, sendo respaldado pela resolução 381/2011. A partir de 03 de outubro de 2012, por força de normatizações estabelecidas pelo Conselho Federal de Enfermagem (Resoluções COFEN № 381/2011 e 385/2011) a coleta de Citologia Oncótica pelo método Papanicolau, será privativa do profissional Enfermeiro.

De acordo com o Ministério da Saúde (2016), o profissional enfermeiro que integra a equipe de atenção básica, possui atribuições como realizar consulta de enfermagem, solicitação de exames, prescrição de medicamentos de acordo com os protocolos firmados pelos programas do Ministério da Saúde e medidas leais do conselho deste profissional.

\subsubsection{EFICÁCIA NA REALIZAÇÃO DO EXAME PAPANICOLAU}

O enfermeiro tem total responsabilidade pela coleta de material cervical e confecção do esfregaço, necessita de forma contínua atualizar-se e aperfeiçoar-se sobre a referida temática. Segundo o Ministério da Saúde (2016), a técnica de coleta do material para o exame preventivo do colo do útero consiste na coleta de secreção externa do útero (ectocérvice) e outra da parte interna (endocérvice), sendo introduzido um especulo vaginal e procede-se uma escamação ou esfoliação da superfície externa e interna do colo do útero por meio de uma espátula de madeira (espátula de Ayre) e de uma escovinha respectivamente.

A fim de obter um bom resultado no diagnóstico, é essencial que haja uma coleta de material adequada e correta, realizada por profissional preparado tecnicamente

RC: 89652

Disponível em: https://www.nucleodoconhecimento.com.br/saude/enfermeiro-na-prevencao 
preservando material de qualidade. As recomendações são que as mulheres não devem estar menstruadas; se possível, coletar no $5^{\circ}$ dia após o termino da menstruação. Não deve ter realizado ultrassonografia intravaginal por dois dias antes do exame e um pequeno sangramento de origem não menstrual não impede a coleta do exame.

A coleta em virgens, cuja quais nunca tiveram relação sexual, deve ser realizada de preferência pelo médico (se for de extrema necessidade), a coleta em mulheres grávidas deve ser realizada somente a ectocervical e da parede vaginal, e em mulheres histerectomizadas deve se verificar se o colo ainda está integro e realizar a coleta normalmente, se não tiver, realizar coleta da parede vaginal.

Durante a consulta de enfermagem à mulher, o enfermeiro além de realizar o exame Papanicolau, deve fazer o exame clínico das mamas, orientando e estimulando as mulheres a realizarem o autoexame das mamas, uma vez que a maior incidência de mortalidade no sexo feminino é devido ao câncer de mama. O profissional enfermeiro é um educador em saúde e é de suma importância que este esteja preparado para atuar na dimensão do cuidar, prevenindo e detectando o câncer cérvico-uterino, contribuindo para redução da mortalidade por esta patologia.

Como dito anteriormente, o enfermeiro tem um papel muito importante frente essa patologia, não só na função curativa, mas principalmente na preventiva, em que através dele é exercida de forma positiva sobre as mulheres, uma vez que muitas já passaram por algum desconforto no momento da coleta ou tenham deixado à consulta sem que suas dúvidas sobre a relevância desse exame e seus benefícios fossem sanadas, criando automaticamente uma barreira entre o público-alvo e a prevenção levada através do profissional enfermeiro.

É importante a atuação do enfermeiro neste meio, pois no momento que ele oferta os seus conhecimentos para o bem da saúde da mulher de forma segura e confortável para a mesma, ajudando a diminuir o desconforto no momento da coleta do preventivo e fazendo-a se sentir a vontade para esclarecer suas dúvidas, os resultados positivos RC: 89652 
são notórios, a busca por esse serviço orientado pelo enfermeiro se torna rotina, a mulher se conscientiza que depende apenas dela se manter saudável e ela se transforma em um agente multiplicador em sua comunidade.

\section{ANÁLISES DE DADOS}

Ao fazermos o levantamento bibliográfico sobre câncer de colo do útero encontramos diversos autores que já estudam o tema e procuram soluções para diminuir a incidência da lesão.

\subsection{LESÕES PRECURSORAS DO CÂNCER DE COLO DO ÚTERO}

O Ministério da Saúde (2016), trás a definição clínica para Condilomatose, como uma doença que se manifesta principalmente através de lesões únicas ou múltiplas podendo ter tamanhos variados, geralmente encontradas na glande, suco e na região perianal no homem, vulva, vagina ou colo do útero na mulher.

Estudos relatam que as lesões precursoras são encontradas cinco vezes mais em mulheres que possuem as DSTs, visto que essas doenças facilitam a infecção pelo HPV, consequentemente, aumentando o risco de desenvolver o câncer de colo de útero. Segundo informações do INCA (s.d.), existe mais de 200 subtipos de HPV, mais somente o subtipo de alto risco estão correlacionados com NICs de alto grau e com câncer de colo uterino.

Desta forma o autor Silva (2006), destaca que:

Os subtipos do HPV são divididos em 3 grupos: 1. Baixo risco, correspondendo a 6, 11, 42, 44, 70 e 73; 2: Grupo de alto risco oncogênico associados à lesões intra epiteliais e ao câncer, sendo os subtipos 16, 18, 31, 33, 34, 35, 39, 45, 51, 52, 56, 58, 59, 66 e 68, e 3. Grupo intermediário, que corresponde aos subtipos 26, 54 e 70 a relação entre os subtipos de HPV de alto risco, as lesões precursoras e o câncer de colo uterino ficou constatada através de estudos que identificou o DNA do HPV de alto risco em 84 a 99,7\% dos cânceres de colo uterino (SILVA, 2006).

RC: 89652

Disponível em: https://www.nucleodoconhecimento.com.br/saude/enfermeiro-na-prevencao 
Diante do exposto, as estatísticas já comentadas nessa pesquisa expõem que este vírus tem influência no aumento do câncer de colo do útero fazendo-se necessário um rastreio rigoroso dessa patologia, sendo assim necessário que o enfermeiro esteja sempre integrado aos programas de prevenção do câncer de colo do útero.

\subsection{PRÁTICAS EDUCATIVAS REALIZADAS PELO ENFERMEIRO NA PREVENÇÃO DO CÂNCER DE COLO DO ÚTERO}

Silva (2008) menciona que o controle do câncer de colo do útero depende de ações voltadas para a área de promoção à saúde, priorizando a prevenção de doenças e a qualidade de vida. $O$ enfermeiro pode interferir nessas ações realizando visitas domiciliares e consultando formas humanizadas de procedimentos de exames, como por exemplo o citado Papanicolau. Assim sendo, visa contribuir para um melhor atendimento as mulheres, podendo encaminhar a mesma para um atendimento adequado de forma rápida e objetiva.

Autores como Vale et. al. (2010); Oliveira; Spiri (2006) e o próprio INCA (2019), mencionam sobre a Estratégia de Saúde da Família, cujo programa do SUS, possui como objetivo reorientar o modelo assistencial e incluir a prática e a articulação de prevenções e promoção da saúde. Tal programa, permite que através de uma expansão e qualificação da atenção primária, permita gerir de forma única e objetiva um cenário favorável a reorganização do modo de rastreamento do câncer do colo do útero em mulheres.

Dentro deste contexto, Parada et al. (2008) explicam que o enfermeiro exerce papel essencial dentro das equipes de Estratégia Saúde da Família (ESF) e a sua conduta ao longo do atendimento pode ser um fator determinante na assistência prestada.

O enfermeiro tem desempenhado um papel de suma importância, pois tem participado assiduamente de todo processo de promoção, tendo como medidas de prevenção: 0 rastreamento, a consulta de enfermagem, a educação em saúde, a inclusão do homem, a busca ativa das mulheres faltosas através das visitas domiciliares e hoje a RC: 89652

Disponível em: https://www.nucleodoconhecimento.com.br/saude/enfermeiro-na-prevencao 
vacinação contra o HPV (somente distribuída nas redes privadas). Por isso é importante que o enfermeiro adquira conhecimentos sobre a população onde irá prestar assistência, como: a cultura, as condições socioeconômicas, o conhecimento da doença e os serviços de prevenção disponíveis nas Unidades Básicas de Saúde (UBS).

O profissional enfermeiro deve conscientizar-se que sua atuação não se restringe apenas a coleta dos exames de Papanicolau, mas também aos fatores citados anteriormente, tornando necessário traçar estratégias para que a população aceite sem restrições as informações fornecidas.

A mulher como principal beneficiária da prevenção do câncer de colo uterino deve ser esclarecida de como é feito a prevenção, quais são as etapas do exame de Papanicolau, como descrito no Manual de Procedimentos Técnicos e Administrativos (2004). Assim, a enfermagem estabelece vínculos de confiança com a população, fazendo com que seja atuante na prevenção primária contra o câncer de colo uterino.

Pinho e França Júnior (2003) melhor recurso utilizado contra o câncer de colo de útero é a prevenção através do exame Papanicolau, momento este que o enfermeiro da Estratégia Saúde da Família (ESF) utiliza para estar orientando à mulher, levando-a a compreender a importância da prevenção do câncer do colo do útero, criando uma maior interação profissional-usuário que se tornam armas úteis para superar esse problema, trazendo resultados favoráveis a população feminina.

As estratégias de prevenção secundária do câncer do colo do útero, definida por Pinho e França Júnior (2003), consistem no diagnóstico precoce das lesões do colo do uterino antes mesmo de tornarem invasivas, permitindo assim técnicas de rastreamento e testes de Papanicolau, entre outros. Os autores mencionam que o teste de DNA do vírus Papiloma humano, em esfregaços citológicos ou espécimes histopatológicos é considerado o mais efetivo e eficiente. É fundamental que os serviços de saúde orientem o que é, e qual a importância do exame preventivo, pois

$\mathrm{RC}: 89652$

Disponível em: https://www.nucleodoconhecimento.com.br/saude/enfermeiro-na-prevencao 
a sua realização periódica permite reduzir a mortalidade por câncer do colo do útero na população de risco (INCA, 2019).

A maioria dos estudos traz como eficácia para a prevenção e a cura deste tipo de câncer o exame preventivo, mas ressalta-se que apenas a coleta do material através do Papanicolau não é suficiente para a prevenção, sendo imprescindível a inclusão das práticas educativas.

Pirelli (2002), menciona que a prevenção do câncer de colo de útero deve envolver um conjunto positivo de ações educativas com a finalidade de atingir uma grande parte das mulheres dentro do fator de risco. A educação, portanto, é um indicador crucial de qualidade, porque representa a estratégia básica de formação humana, significa "aprender a aprender, saber pensar, para poder melhor intervir e inovar. (DEMO, 1998).

É imprescindível que o enfermeiro também estenda a educação ao homem sobre esse assunto, pois em certas situações o parceiro da mulher com o câncer de colo do útero pode ser o transmissor do vírus HPV (Papilomavírus humano) levando essa mulher a desenvolver as lesões do câncer ou até mesmo a reinfecção após o tratamento, por isso a importância do uso da camisinha, seja ela masculina ou feminina, quebrando até mesmo o preconceito do homem sobre o uso do preservativo, que é a melhor forma de se proteger.

\section{CONSIDERAÇÕES FINAIS}

Notou-se que a população não tem conhecimento dos fatores de risco para câncer de colo do útero e consequentemente, não sabem como evitá-los, fazendo-se necessário a educação na população, que quando alertada se conscientiza de seu papel na prevenção do câncer do colo do útero.

Para que a consulta de enfermagem consiga ampliar suas práticas educativas sobre como o exame Papanicolau e a conscientização da população de se prevenir contra

RC: 89652

Disponível em: https://www.nucleodoconhecimento.com.br/saude/enfermeiro-na-prevencao 
o câncer de colo útero é de suma importância conhecer os costumes, a cultura e crenças da população alvo. Para tal, é necessário que o enfermeiro seja inserido nesta sociedade, empenhando-se em construir uma comunicação com a paciente e seus familiares, galgando confiança e segurança, assim criando um vínculo com a mulher favorecendo a aproximação entre a paciente e o enfermeiro.

É inevitável deixar de refletir sobre conhecimento inadequado e insuficiente ofertado a algumas mulheres sobre esta doença, já que a maioria delas frequenta os serviços de saúde e até mesmo já realizaram uma ou mais vezes o exame de Papanicolau. Através dessa reflexão, é importantíssimo que o enfermeiro se questione sobre os ganhos que ele pode acrescentar na vida desta mulher ao ser consultada por ele, disponibilizando um serviço com total atenção tratando-a com singularidade e respeito, já que muitas criam certas resistências ao se consultarem com o enfermeiro e não com o médico, que é de rotina para algumas. Devido a esse motivo, o enfermeiro com profissionalismo e ética tem que mostrar sua capacidade de realizar uma boa consulta e coleta do material, fazendo com que a mulher deixe o serviço de saúde satisfeita com o atendimento e colocando por terra suas dúvidas quanto a consulta com o enfermeiro.

As atuações do enfermeiro são inúmeras, onde se destacam: a redução da espera pela consulta, a diminuição do incômodo na realização do exame, flexibilidade de horário, integração do homem na prevenção do câncer de colo do útero e a conscientização e educação da população em relação aos cuidados com a sua saúde.

Reunimos então algumas práticas educativas utilizadas pelo enfermeiro que são elas: as visitas domiciliares, e a consulta de enfermagem de forma humanizada e integralizada, tendo assim uma excelente oportunidade para educá-la ao longo do exame Papanicolau. Desta forma, contribuiremos para o melhor atendimento promovendo, mantendo e restaurando a saúde da população feminina. A educação e a promoção da saúde estão ligadas por uma meta de encorajar as pessoas a procura

RC: 89652

Disponível em: https://www.nucleodoconhecimento.com.br/saude/enfermeiro-na-prevencao 
de um bem estar de forma que elas possam viver com mais saúde e prevenir as doenças inevitáveis.

Os resultados alcançados através desta pesquisa servem como incentivo para uma reflexão à cerca não só da atuação do enfermeiro na prevenção do câncer de colo do útero, mas também de sua importância e autonomia, conscientizando-nos do nosso futuro papel na sociedade, do conhecimento que devemos adquirir e aprimorarmos continuamente, mas fazendo com que nos sintamos mais seguras ao enfrentarmos as doenças e criarmos instrumentos e mecanismos para a prevenção.

\section{REFERÊNCIAS}

BRASIL (1990) Lei $\mathbf{n} . \mathbf{8} 8.080 / 1990$. Conselho Nacional da Saúde. Disponível em: http://conselho.saude.gov.br/legislacao/lei8080.htm. Acesso em: 15 jun. 2021.

BRASIL (2006). Política nacional de atenção básica. Ministério da Saúde, Secretaria de Atenção à Saúde, Departamento de Atenção à Saúde. - Brasília: Ministério da $\quad 2006 . \quad$ Saúde, Disponível em: https://bvsms.saude.gov.br/bvs/publicacoes/politica_nacional_atencao_basica_2006. pdf Acesso em: 15 jun. 2021.

Brasil (2016). Ministério da Saúde. Protocolos da Atenção Básica: Saúde das Mulheres Instituto Sírio-Libanês de Ensino e Pesquisa - Brasília: Ministério da Saúde, 2016. 230 p. Disponível em: Acesso em: https://bvsms.saude.gov.br/bvs/publicacoes/protocolos_atencao_basica_saude_mul heres.pdf 15 jun. 2016.

CARVALHO, G. I.; SANTOS, L. Sistema Único de Saúde: comentários à lei orgânica de saúde (Leis n. 8.080/90 e n. 8.142/90). 3ª̣ed. Campinas: UNICAMP, 2002. 330 p.

CESTARI, M. E. W. A Influência da cultura no comportamento de prevenção do câncer.

2005

Disponível

em:

RC: 89652

Disponível em: https://www.nucleodoconhecimento.com.br/saude/enfermeiro-na-prevencao 
https://www.teses.usp.br/teses/disponiveis/22/22132/tde-10052005-

112100/publico/Cestari_MEW.pdf. Acesso em: 15 jun. 2021

COFEN-12 (2015) Parecer De Conselheiro Federal $\mathbf{N}^{\circ}$ 190/2015/COFEN.

Disponível em: http://www.cofen.gov.br/parecer-de-relator-n-1902015_48415.html. Acesso em: 15 jun. 2021.

DEMO, P. Educação e qualidade. 4. ed. São Paulo: Papirus, 1998. 160 p.

DENZIN; NORMAN K.; LINCOLN, YVONNA S. O Planejamento da Pesquisa Qualitativa - Teorias e Abordagens. 2 Edição. São Paulo: Artmed, 2006.

GIL, Antonio C. Métodos e técnicas de pesquisa social. São Paulo: Atlas. 1999.p. 43.

GIL, Antonio C. Métodos e técnicas de pesquisa social. São Paulo: Atlas.2007. p.42.

HERBST, Hans Wolfgang. Tratado de ginecologia. v.3. 3.ed. São Paulo: Roca, 2000. p. 2129.

INCA (1997). MINISTÉRIO DA SAÚDE. Instituto Nacional de Câncer (Brasil). Programa

Viva Mulher. Disponível em: https://rbc.inca.gov.br/site/arquivos/n_43/v02/sumario.html Acesso em: 15 de jun. 2021.

INCA (2019). MINISTÉRIO DA SAÚDE. Instituto Nacional de Câncer (Brasil). Câncer no Brasil: dados dos registros de base populacional. Disponível em: https://www.inca.gov.br/publicacoes/ivros/cancer-no-brasil-dados-dos-registros-debase-populacional . Acesso em: 15 jun. 2021.

RC: 89652

Disponível em: https://www.nucleodoconhecimento.com.br/saude/enfermeiro-na-prevencao 
INCA (2020) - MINISTÉRIO DA SAÚDE. Instituto Nacional de Câncer José Alencar Gomes da Silva (INCA). Estimativa | 2020Incidência de Câncer no Brasil. Disponível em: https://www.inca.gov.br/sites/ufu.sti.inca.local/files/media/document/estimativa-2020incidencia-de-cancer-no-brasil.pdf Acesso em: 15 junho de 2021.

INCA (2021). MINISTÉRIO DA SAÚDE. Instituto Nacional de Câncer (Brasil).. Câncer do colo do útero. Disponível em: https://www.inca.gov.br/tipos-de-cancer/cancer-docolo-do-utero Acesso em: 15 de jun. 2021.

MANUAL DE PROCEDIMENTOS TÉCNICOS E ADMINISTRATIVOS. Coleta do Papanicolau e ensino do autoexame da mama. Ministério da Saúde. Instituto Nacional do Câncer e Secretaria de Estado da Saúde, 2004.

MINISTÉRIO DA SAÚDE (2016). Secretaria de Atenção à Saúde. Departamento de Atenção Básica. Controle dos cânceres do colo do útero e da mama. Brasília: Ministério da Saúde; $2013 . \quad$ Disponível em: https://bvsms.saude.gov.br/bvs/publicacoes/controle_canceres_colo_utero_2013.pdf Acesso em: 15 jun. 2021.

OLIVEIRA, E. M.; SPIRI, W. C. Programa Saúde da Família: a experiência de equipe multiprofissional. Rev. Saúde Pública, v. 40, n. 4, p. 727 - 733, 2006.

PARADA, R. et al. A política nacional de atenção oncológica e o papel da atenção básica na prevenção e controle do câncer. Revista de Atenção Primária à Saúde, v.11, n. 2, p.199 - 206, abr./jun. 2008.

PINHO, A. de A.; FRANÇA JÚNIOR, I. Prevenção do Câncer de Colo do Útero: um modelo teórico para analisar o acesso e a utilização do teste de Papanicolau. Revista Brasileira de Saúde Materno Infantil, Recife, v. 3, n. 1, 2003.

SILVA S.E.D.; VASCONCELOS E.V.; SANTANA M.E.; LIMA V.L.A.; CARVALHO F.L.; MAR D.F. Representações sociais de mulheres amazônicas sobre o exame RC: 89652

Disponível em: https://www.nucleodoconhecimento.com.br/saude/enfermeiro-na-prevencao 
Papanicolau: implicações para a saúde da mulher. Escola Anna Nery. Revista de Enfermagem, v. 12, n. 4, p. 685 - 692, dez. 2008.

SILVA T.T, GUIMARÃES M.L, BARBOSA M.I.C, PINHEIRO M.F.G, MAIA A.F. Identificação de tipos de papilomavirus e de outros fatores de risco para neoplasia intra-epitelial cervical. Revista Brasileira de Ginecologia Obstetrícia. 2006; 28(5):285-91. Disponível em: http://www.scielo.br/pdf/rbgo/v28n5/a04v28n5.pdf. Acesso em: 15 Jun. 2021.

SMELTZER, S.C; BARE, B.G. Tratado de enfermagem médico-cirúrgica. 9 ed. Rio de Janeiro: Guanabara Koogan, 2002.

SOOST HJ, Lange HJ, Lehmacher W, Ruffing-Krellmann B. A validação da citologia cervical. Sensibilidade, especificidade e valores preditivos. Traduzido do original: The validation of cervical cytology: sensitivity, specificity and predictive values. Acta Cytol 1991; 35: 8-13.

VALE, D. B. A. P.; MORAES, S. S.; PIMENTA, A. L.; ZEFERINO, L. C. Avaliação do rastreamento do câncer do colo do útero na Estratégia Saúde da Família no Município de Amparo, São Paulo, Brasil. Caderno de Saúde Pública, v. 26, n.2, p. 383 - 390, fev. 2010.

Enviado: Junho, 2021.

Aprovado: Junho, 2021. 